\title{
Fisio card game: um jogo didático para o ensino da fisiologia na educação
}

\section{básica}

\author{
Fisio card game: an educational game for physiology teaching in basic education
}

Tarcila de Araújo Alves' ${ }^{1}$ Lucas de Souza Falcão ${ }^{1}$, Aline Tatiane Souza', Thaís Santiago do Amaral', Sheila Pereira de Lima ${ }^{1}$, Thaís Billalba Carvalho ${ }^{*}$

${ }^{1}$ Universidade Federal do Amazonas - Curso de Ciências Biológicas

${ }^{2}$ Universidade Federal do Amazonas - Instituto de Ciências Biológicas, Departamento de Ciências Fisiológicas, Laboratório de Fisiologia Animal

*e-mail: thaisbillalba@yahoo.com.br

\begin{abstract}
Resumo
O ensino de fisiologia apresenta dificuldades em dois pontos importantes: 1. a fragmentação do estudo dos sistemas biológicos, que dificulta a visão da integração sistêmica e do funcionamento do organismo; e 2. a dificuldade que os estudantes apresentam para memorizar as estruturas anatômicas e suas funções. Esses dois aspectos afastam o interesse dos alunos em aprender os conteúdos de fisiologia e, neste contexto, apresentamos o Fisio card game. Este jogo consiste na formação de grupos de cartas com relação fisiológica que objetiva aumentar a visão integrada entre os sistemas biológicos e auxiliar na memorização de termos encontrados neste conteúdo. Após a elaboração, o referido jogo didático foi aplicado para estudantes do terceiro ano do ensino médio e foram respondidos questionários que indicam que o jogo pode auxiliar nos dois pontos já citados e, portanto, pode ser usado como um facilitador no processo de ensino/aprendizado por despertar interesse nos alunos.
\end{abstract}

Palavras-chave: Morfofisiologia; Jogo Lúdico; Integração Sistêmica.

\begin{abstract}
The physiology teaching struggles in two major points: 1. the study of biological systems in fragmented pieces, making harder to build an integrated systemic and functioning view of the organism; and 2. the difficulty presented by students in memorizing anatomic structures and to match them with their functions. These two aspects decrease students' interest in learning physiology subjects, and in this context we present the Fisio card game. This game consist in grouping cards showing physiological relationship, aiming to enhance the integrated view among biological systems, and to assist the memorization definitions related to this content. Fisio card game was field tested with senior high school students' who answered a survey about how the game can help these two points already mentioned, being a facilitator in the teaching/learning process to engage students.
\end{abstract}

Keywords: Morphophysiology; Playfulness game; Systemic integration. 


\section{Ficha da atividade}

\begin{tabular}{|c|c|}
\hline Título & $\begin{array}{l}\text { Fisio card game: um jogo didático para o ensino da fisiologia na educação } \\
\text { básica. }\end{array}$ \\
\hline Público alvo & Alunos do terceiro ano do ensino médio. \\
\hline $\begin{array}{l}\text { Disciplinas } \\
\text { relacionadas }\end{array}$ & Ciências, Biologia e Educação Física. \\
\hline $\begin{array}{l}\text { Objetivos } \\
\text { educacionais }\end{array}$ & $\begin{array}{l}\text { Estimular o discente a relacionar de forma integrada a estrutura e o } \\
\text { funcionamento dos sistemas do corpo humano ajudando-o na fixação de nomes } \\
\text { necessários para o entendimento do conteúdo e para ter uma visão integradora } \\
\text { sobre os sistemas fisiológicos. }\end{array}$ \\
\hline $\begin{array}{l}\text { Justificativa } \\
\text { de uso }\end{array}$ & $\begin{array}{l}\text { Em geral, os alunos do ensino médio apresentam dificuldades para visualizar os } \\
\text { processos fisiológicos de modo integrado. Diante do exposto, elaboramos um } \\
\text { jogo didático que tem por objetivo estimular os discentes a pensar em sistemas } \\
\text { fisiológicos e integração por meio da competitividade. }\end{array}$ \\
\hline $\begin{array}{l}\text { Conteúdos } \\
\text { trabalhados }\end{array}$ & $\begin{array}{l}\text { Sistema Endócrino, Sistema Sensorial, Sistema Nervoso, Sistema Reprodutor, } \\
\text { Sistema Renal, Sistema Respiratório, Sistema Digestório e Sistema Circulatório. }\end{array}$ \\
\hline $\begin{array}{l}\text { Estimativa de } \\
\text { duração }\end{array}$ & 25 minutos \\
\hline $\begin{array}{l}\text { Materiais } \\
\text { utilizados }\end{array}$ & $\begin{array}{l}\text { Folhas de papel A4 para impressão das cartas, tinta para impressão colorida, } \\
\text { papel casca-de-ovo/cartão para base das cartas, cola branca e tesoura. }\end{array}$ \\
\hline
\end{tabular}




\section{Introdução}

O ensino de fisiologia na educação básica costuma ser dividido em sistemas biológicos com o objetivo de facilitar sua aprendizagem, contudo, tal escolha pode ter o efeito contrário, pois essa abordagem distorce a integração do organismo levando o aluno a pensar nos processos funcionais de maneira fragmentada, o que gera dificuldades para a sua compreensão [1]. Além disso, a dificuldade na memorização de estruturas anatômicas afeta diretamente o ensino da fisiologia, pois, sem este conhecimento, o aluno não consegue compreender o funcionamento dos sistemas.

De fato, o ensino de Ciências tem por objetivo estimular a construção de um aprendizado significativo que supere apenas a memorização de nomes, regras e leis, porém, para que isso ocorra é fundamental que o estudante identifique no mínimo a nomenclatura utilizada na disciplina [2]. Além disso, devem ser desenvolvidas competências e habilidades definidas pelo MEC, tais como: Compreender interações entre organismos e ambiente, em particular aquelas relacionadas à saúde humana, relacionando conhecimentos científicos, aspectos culturais e características individuais; Identificar padrões em fenômenos e processos vitais dos organismos, como manutenção do equilíbrio interno, defesa, relações com o ambiente, sexualidade, entre outros; e Interpretar modelos e experimentos para explicar fenômenos ou processos biológicos em qualquer nível de organização dos sistemas biológicos [3].

Barbão e Oliveira [4] mostraram que alunos de ensino médio de escolas públicas apresentam dificuldade de conceituação e/ou compreensão dos termos da Biologia. No entanto, para que se compreenda a fisiologia é de suma importância o conhecimento sobre o nome e localização de estruturas e órgãos relacionados, o que permitirá a visão integrada do funcionamento do organismo.

A motivação do aluno também tem um papel fundamental na aprendizagem significativa, pois esta requer que o agente se interesse pelo assunto. A motivação pode ser entendida como o que inicia e move as ações de um indivíduo [5, 6]. Atualmente, existem muitas inovações tecnológicas como animações, jogos digitais, cartas ou de perguntas e respostas além de técnicas como a dramatização ou outras dinâmicas de grupo que visam estimular a aprendizagem dos alunos. Os recursos didáticos motivadores, como os jogos didáticos, são ferramentas fundamentais para a aquisição de conhecimento e a adoção de tais inovações na prática docente deve ser considerada quando se tem por objetivo a apropriação de conhecimento por parte do discente [7, 8].

Os jogos didáticos se mostram uma estratégia com grande potencial para a 
facilitação do processo ensino/aprendizagem, uma vez que podem estimular o interesse dos alunos [9, 10]. Cunha [11] afirma que jogos didáticos são produzidos para determinadas aprendizagens e diferenciam-se de outros materiais pedagógicos por envolverem o aspecto lúdico, sendo utilizados como alternativa para a aprendizagem de conteúdos de difícil compreensão [12].

Vários objetivos podem ser considerados durante a utilização dos jogos didáticos, tais como: o desenvolvimento da inteligência e da personalidade, que são fundamentais para a construção de conhecimentos; o desenvolvimento da sensibilidade, que atua no sentido de estreitar laços de amizade e afetividade; a socialização; o envolvimento da ação e do desafio e a mobilização da curiosidade e a criatividade [13]. Além disso, as atividades lúdicas permitem trabalhar a ansiedade, testar os próprios limites, aumentar a segurança e a autoestima, o desenvolvimento da autonomia, o aprimoramento da coordenação motora, o aumento da concentração e da atenção e estimular a ampliação do raciocínio lógico, de estratégias e da criatividade [13, 14].

Diante do exposto, os jogos lúdicos instigam o aluno a aprender de forma interativa e dinâmica, favorecendo a construção do processo de aprendizagem a partir da associação de conhecimentos prévios com o cotidiano. Neste contexto, o professor apresenta papel fundamental como condutor, estimulador e avaliador da aprendizagem $[15,16]$. De acordo com Campos e colaboradores [12], o jogo lúdico possibilita a aproximação dos alunos ao conhecimento científico, pois os leva a uma vivência, ainda que virtual, de problemas ou conceitos abstratos ou de difícil associação com a realidade dos estudantes.

Considerando que os conceitos sobre os sistemas e suas funções são abordados de maneira dissociada durante o ensino médio, o uso de jogos para a compreensão e fixação de conteúdos de fisiologia se mostra uma alternativa válida e de fácil execução. Assim, elaboramos um jogo didático que tem por objetivo esclarecer e tornar mais evidente os conceitos estruturais básicos de forma a proporcionar ao aluno uma visão integrada da fisiologia.

\section{Material e Métodos}

\subsection{Elaboração do jogo}

O Fisio card game foi elaborado durante a disciplina Prática como Componente Curricular em Fisiologia Humana ministrada para o curso de Licenciatura em Ciências Biológicas da Universidade Federal do Amazonas. Durante a elaboração do referido jogo 
foi possível verificar as diferenças entre os assuntos abordados na educação básica e os conteúdos ministrados na graduação. Assim, o exercício de avaliar os livros didáticos de ensino médio e a experiência prática na conversão do conteúdo de fisiologia para um jogo lúdico foi muito proveitosa, pois evidenciou a relação direta e a importância da participação do aluno e do professor no processo de ensino e aprendizagem. Além disso, todo o processo de teorização do jogo até a confecção das cartas, sua aplicação em sala de aula e análise de resultados demonstraram a necessidade de buscar alternativas metodológicas que estimulem a problematização e a contextualização para o ensino de conceitos básicos e que contribuam para a construção do conhecimento.

\subsection{Confecção e recursos utilizados}

O jogo Fisio card game é constituído por 56 cartas divididas em oito categorias: sistema nervoso, sensorial, respiratório, circulatório, endócrino, digestório, renal e reprodutor, tendo ainda oito cartas adicionais de hormônios e três cartas coringas. Cada sistema possui seis cartas com estruturas e termos relacionados ao mesmo (Apêndice A), apresenta-se na Tabela 1 as cartas pertencentes aos seus respectivos sistemas.

Tabela 1. Identificação das cartas que representam cada sistema.

\begin{tabular}{cl}
\hline Sistema & \multicolumn{1}{c}{ Cartas } \\
\hline Nervoso & encéfalo, impulso nervoso, reflexo e neurônio \\
Sensorial & visão, boca, receptores sensoriais, narinas, audição e tato \\
Respiratório & oxigênio, pulmões, alvéolos, faringe, laringe e músculos respiratórios \\
Circulatório & veias, capilares, sangue, linfa, pressão sanguínea e coração \\
Endócrino & hipotálamo, tireóide, suprarrenais, paratireóides e hipófise \\
Digestório & pâncreas, intestino, absorção, fígado, esôfago e dentes \\
Renal & rins, água, uréia, bexiga, glomérulo e filtração \\
Reprodutor & ovário, útero, testículos, ovulação, puberdade e amamentação \\
Hormônios & hormônio antidiurético, insulina, glucagon, ocitocina, adrenalina, gonadotropinas, \\
Coringas & prolactina e calcitonina \\
\hline
\end{tabular}

O baralho foi elaborado a partir da impressão colorida das cartas em papel A4, no tamanho de 4,5 cm X 7,0 cm e apresenta uma imagem com o nome da estrutura ou uma imagem representativa ao termo fisiológico que a nomeia e o título da carta em destaque. As cartas foram cortadas e coladas em papel casca de ovo, para maior resistência e, em seguida, plastificadas. Uma alternativa é utilizar o papel cartão colorido como base para as cartas. No total foram confeccionados seis baralhos para aplicação do jogo em sala de aula para 33 alunos do terceiro ano do ensino médio. 


\subsection{Modo de Jogar e Regras}

O objetivo do jogo é formar uma trinca de cartas relacionadas entre si, isto é, são consideradas trincas válidas as que são formadas por componentes de um mesmo sistema fisiológico (ex. sistema nervoso: encéfalo, impulso nervoso e neurônio). Outra opção é a formação de trincas de integração direta entre os sistemas, chamadas de trincas integradoras. Neste caso, o aluno deve explicar por que as cartas formam uma integração direta - ex. sangue, adrenalina e $\mathrm{O}_{2}$ formam uma integração em um processo fisiológico, uma vez que quando liberada no sangue a adrenalina aumenta a frequência respiratória e a disponibilidade de $\mathrm{O}_{2}$ para o metabolismo celular. Para isso, os jogadores podem formar trincas a) com a carta trunfo; b) com a carta guia; e c) com as cartas presentes em suas mãos.

Podem jogar de três a cinco pessoas. Os participantes deverão sentar-se em forma de círculo e as cartas que compõem o jogo deverão ser embaralhadas. Cada jogador receberá cinco cartas viradas com a face que contém a informação voltada para baixo, de modo que os demais participantes não leiam seus conteúdos. O restante do baralho deve ser empilhado, com as cartas viradas para baixo, e disposto no centro do círculo, formando um monte de compra que esteja ao alcance de todos os jogadores quando estes precisarem. As cartas descartadas deverão ser dispostas viradas para cima na mesa, ao lado do monte de compra, para que sejam compradas pelos outros jogadores.

O primeiro participante a jogar será aquele que embaralhou e distribuiu as cartas e o jogo seguirá em sentido horário. Ele deverá virar a primeira carta do monte de compras - essa é a carta trunfo, que não poderá ser alterada e poderá ser utilizada por todos os jogadores para formar trincas, caso tenham duas cartas que sejam relacionadas com a carta trunfo.

O mesmo jogador escolherá dentre as cinco cartas da sua mão a carta guia, e deverá colocá-la virada para cima na mesa. A carta guia permanecerá na mesa até algum jogador formar uma trinca com ela. O jogador que pegar a carta guia para formar uma trinca, deverá escolher outra carta guia dentre as cartas da sua mão. O participante encerrará sua jogada quando comprar uma carta do monte de compras. Os jogadores poderão ter no mínimo três e no máximo cinco cartas na sua mão, devendo descartar as cartas excedentes no monte de descarte. As cartas referentes aos conceitos de 'Equilíbrio, 'Regulação' e 'Entropia' são chamadas de coringas visto que podem ser utilizadas para completar qualquer trinca. 
A carta de cima do monte de descarte poderá ser comprada somente pelo jogador à esquerda daquele que realizou o descarte e assim em diante. $O$ jogador que escolher fazer isso poderá continuar sua jogada, ou seja, poderá colocar trincas na mesa, caso seja possível. Sua jogada se encerrará no momento em que comprar uma carta do monte de compras.

O jogo finaliza após cinco rodadas. O jogador que tiver colocado mais trincas na mesa vence o jogo. No caso de empate, ganhará aquele que tiver feito trincas que sejam constituídas por cartas de mais de um sistema, ou seja, trincas integradoras.

\subsection{Aplicação do jogo}

Com o objetivo de avaliar a importância da aplicação de novas estratégias de ensino para Ciências e Biologia na educação básica e de tornar o conhecimento científico mais concreto para o discente, o jogo Fisio card game foi aplicado para 33 alunos do terceiro ano do ensino médio (Figura 1). De acordo com os Parâmetros Curriculares Nacionais para o Ensino Médio - Ciências da Natureza, Matemática e suas Tecnologias [16], a diversificação dos processos vitais e as diferentes estratégias fisiológicas utilizadas para resolver as necessidades básicas dos seres vivos são conteúdos abordados no segundo ano do ensino médio, portanto, os alunos avaliados deveriam ter conhecimento prévio do assunto aplicado.

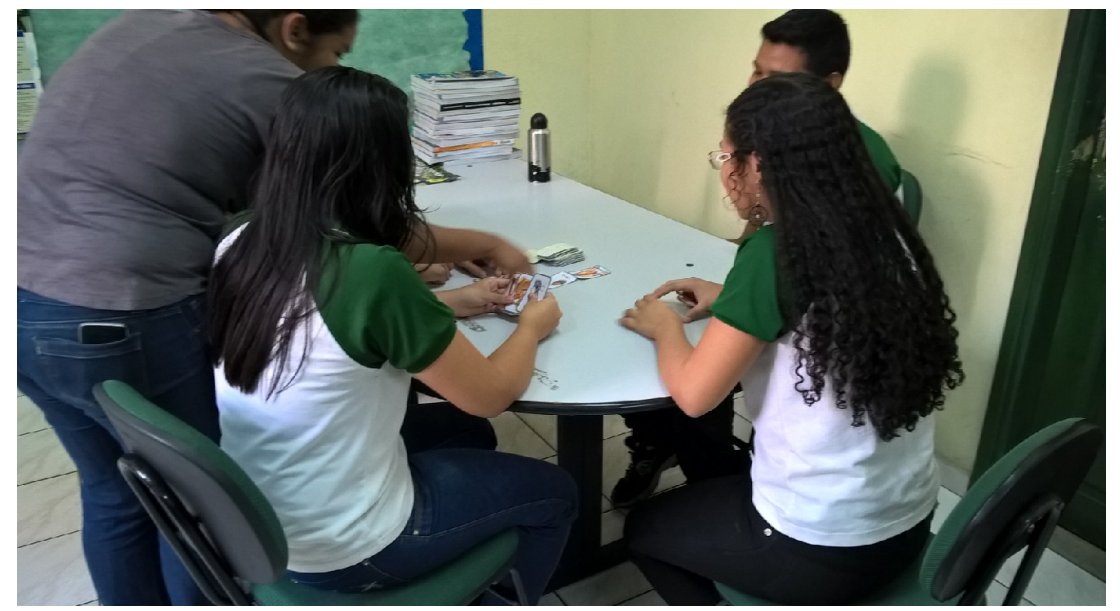

Figura 1. Aplicação do jogo didático para alunos do terceiro ano do ensino médio.

Para verificar os conhecimentos prévios dos discentes foi aplicado um questionário preliminar com cinco questões objetivas e de fácil compreensão, abordando conceitos gerais sobre os sistemas fisiológicos (Apêndice B). Após a aplicação do questionário preliminar, os alunos foram divididos em grupos para testar o jogo Fisio card game.

Antes das partidas, as regras foram explicadas e os grupos foram monitorados 
para o auxílio e esclarecimento de possíveis dúvidas. Em seguida, foi aplicado um questionário de compreensão composto por cinco questões objetivas e que teve como objetivo avaliar se o jogo auxiliou na revisão dos conteúdos de fisiologia e se houve maior compreensão da associação existente entre os sistemas biológicos (Apêndice C).

\section{Resultados e Discussão}

O foco do jogo proposto é a revisão e a associação dos conceitos relativos aos sistemas fisiológicos, pois trabalha diretamente com os componentes do corpo humano e suas respectivas funções. Além disso, o Fisio card game objetiva uma perspectiva integrativa do funcionamento do organismo, por meio da formação de relações entre as cartas que representam componentes de um mesmo sistema fisiológico (trincas válidas) e/ou pela formação de trincas de integração direta entre os sistemas (trincas integradoras).

O questionário preliminar revelou a dificuldade dos alunos para rememorar assuntos do corpo humano abordados no segundo ano do ensino médio. Isso pode ser evidenciado, pois a maioria das respostas informadas pelos alunos foi incorreta, o que indica falta de conhecimento prévio e provável dificuldade durante a participação no jogo (Figura 2).

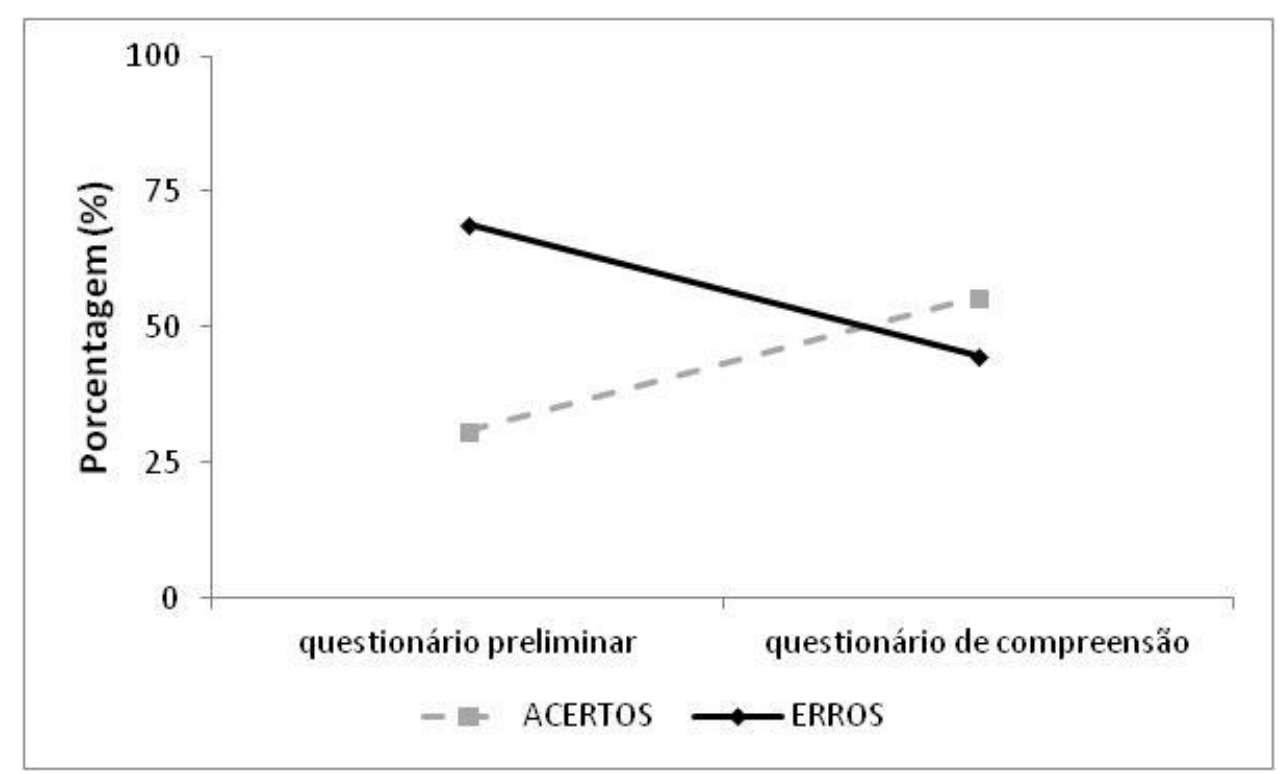

Figura 2. Porcentagem de erros e acertos das respostas apresentadas pelos alunos nos questionários preliminar e de compreensão.

No início do jogo os alunos ficaram confusos devido a quantidade de regras, contudo conforme jogavam, as regras ficaram mais claras com a prática, o que incentivou a continuidade do desenvolvimento das atividades. Todos os grupos conseguiram 
terminar pelo menos uma rodada do jogo, que corresponde à formação de no mínimo uma trinca válida. Os aplicadores atuaram como mediadores durante a realização das partidas e, neste momento, os conhecimentos dos alunos foram testados para estabelecer as associações de cartas com os sistemas as quais estão relacionadas.

Após o término das partidas, os alunos responderam ao questionário de compreensão que apresentou maior nível de dificuldade em relação ao questionário preliminar. Foi observado um bom desempenho dos alunos, considerando a maior porcentagem de acertos nas questões conceituais (Figura 2). Assim, esses resultados indicam que o jogo auxiliou na compreensão e fixação dos conteúdos de fisiologia. Isto também está claramente relacionado com a intervenção dos aplicadores ao explicar os componentes nas cartas, pois o conhecimento da anatomia humana é essencial para o entendimento da fisiologia em geral. O uso das cartas se mostrou uma boa alternativa para ilustrar a integração entre as estruturas o que é fundamental para desconstruir a perspectiva fragmentada do funcionamento do organismo.

Comparando o desempenho nos dois questionários (Figura 2), observamos que os alunos obtiveram uma melhora nas respostas com a execução do jogo, colaborando com a compreensão da integração fisiológica dos sistemas e com a recordação de assuntos abordados anteriormente. Percebemos a falta de motivação que os alunos apresentam para responder as questões de modo mais elaborado e completo, o que torna evidente a necessidade de contextualizar os conteúdos abordados e, consequentemente, estimular o envolvimento dos alunos. De fato, Orlando e colaboradores [17] relatam que o rendimento dos estudantes vai além das expectativas quando se trabalha com a turma de forma interativa e participativa, contextualizando sempre que possível.

Além das questões sobre conhecimentos de fisiologia, foram feitas perguntas sobre a opinião dos alunos em relação ao Fisio card game. Na Figura 3 é possível verificar a opinião dos alunos sobre o aspecto lúdico proporcionado pelo jogo. Além disso, 43\% dos alunos informou que o jogo contribuiu para a maior compreensão da fisiologia humana, pois ajudou a lembrar os conceitos que já sabiam e/ou esclareceu dúvidas.

Os principais aspectos positivos foram a dinâmica apresentada pelo jogo, que estimulou a competitividade dos alunos e os divertiu, além do próprio aprendizado em si.

Esses resultados estão de acordo com outros estudos que evidenciam o uso de modelos tridimensionais, ilustrações e jogos como responsáveis pela melhora na capacidade de adquirir e guardar informações em comparação com métodos de ensino tradicionais $[18,19]$. 
Além disso, jogos didáticos permitem a desconstrução de concepções prévias e a compreensão do tema em foco, atuando como um facilitador do processo de ensino aprendizagem $[9,14,20]$. Os aspectos negativos ressaltados foram a grande quantidade de regras, a falta de conhecimento e de experiência dos alunos em relação ao jogo.

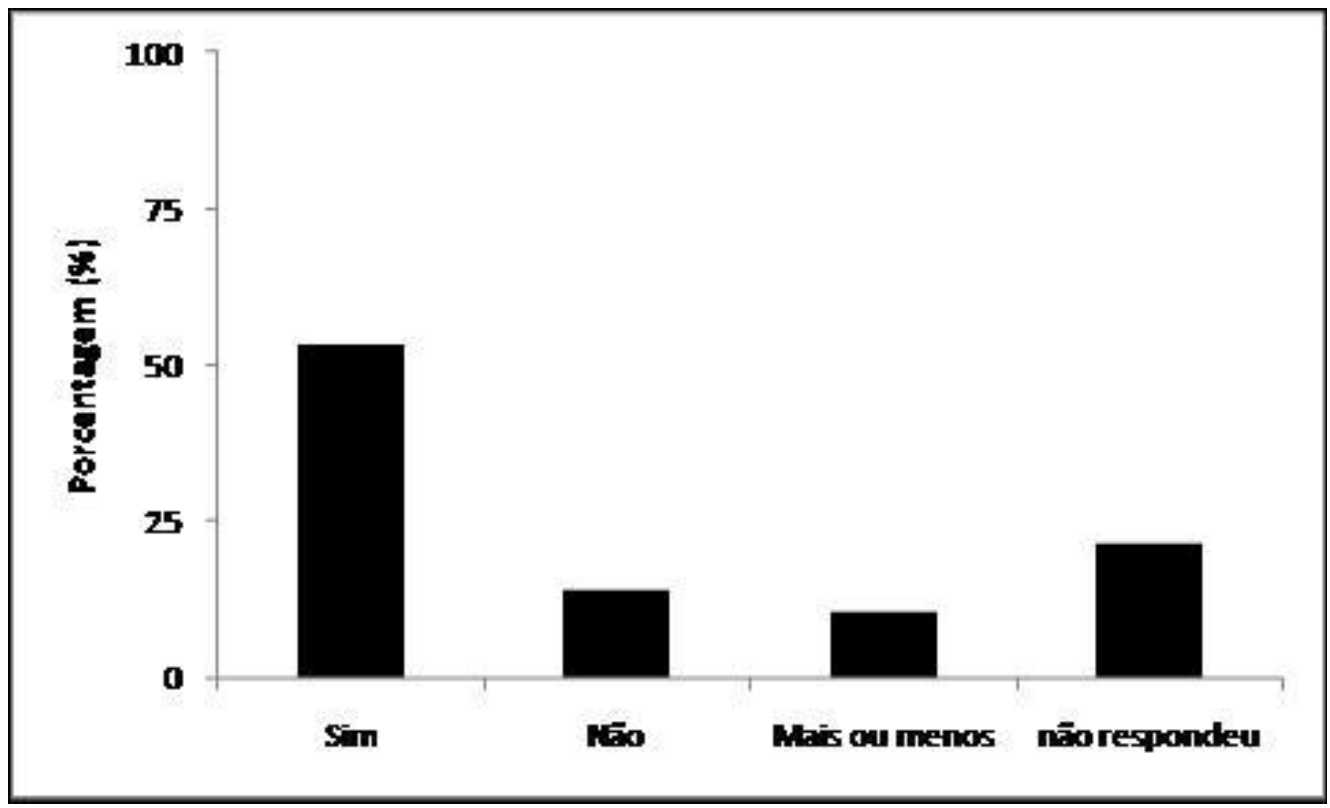

Figura 3. Porcentagem de repostas dos alunos em relação ao aspecto lúdico do jogo.

Como um resultado adicional, podemos refletir sobre os métodos de ensino utilizados na educação que são restritos a um modelo onde os alunos apenas decoram os conteúdos sem ter a percepção total do contexto. No caso dos processos fisiológicos é necessário que sejam adotados métodos que os tornem mais concretos para a compreensão dos educandos.

Vasconcellos [21] discute a importância da construção, pelo educador, de outra concepção de educação, ressaltando a necessidade de se ter clareza sobre os limites e problemas de metodologias expositivas, como o baixo nível de interação sujeito-objeto, de conhecimento e a contribuição na formação de um sujeito passivo e não crítico.

Assim, considera-se que além de construir o conhecimento é necessário mobilizar o sujeito para o conhecimento e estimular a sua elaboração e síntese [21]. Moratori [22] também afirma que o processo de criação está diretamente relacionado à imaginação e a estrutura da atividade com jogos permite o surgimento de situações imaginárias, encaixando-se perfeitamente na situação descrita neste trabalho. 


\section{Considerações finais}

Este é um jogo elaborado com materiais de baixo custo e de fácil acesso para os professores. Suas regras são baseadas em jogos de baralho comuns como pif paf e poker, o que desperta o interesse dos alunos. Durante a execução do jogo em sala de aula, observamos seu uso como uma estratégia motivadora e como instrumento de rememoração e fixação de conteúdo, ou ainda de construção de conhecimentos baseados nas experiências prévias apresentadas pelos alunos.

Além de despertar a competitividade sadia, os princípios da independência e a associação de conhecimento e o raciocínio rápido que são necessários para que o discente possa formar uma trinca ou fazer uma jogada rápida.

Os resultados obtidos mostraram que é necessária a criação de um roteiro ou normas impressas para melhor compreensão das regras. Apesar da dificuldade inicial com alguns nomes de estrutura, o jogo os ajudou a relembrar o conteúdo de fisiologia e fazer associações entre os componentes de diferentes sistemas, mostrando que conseguiram relacionar pelo menos de forma superficial a integração entre os diferentes sistemas em um organismo.

Espera-se que o Fisio card game contribua para a revisão de conceitos morfofisiológicos básicos que, por sua vez, podem auxiliar na visão de um organismo integrado e não fragmentado em sistemas não relacionados.

De modo geral, o referido jogo apresentou resultados positivos sobre sua aplicação, mostrando que seus objetivos foram cumpridos de modo satisfatório e que pode ser utilizado como material didático de apoio para a disciplina de Biologia

- Desse modo, o jogo ainda pode ser ajustado de acordo com as habilidades cognitivas dos alunos com o qual for trabalhado e conforme as necessidades e experiências dos educadores.

\section{Referências}

[1] Vanzela EC, Balbo SL, Justina LAD. A integração dos sistemas fisiológicos e sua compreensão por alunos do nível médio. Arq Mudi 2007; 11(3): 12-9.

[2] Merçon F. Os objetivos das ciências naturais no ensino médio. Revista Eletrônica do Vestibular [periódicos na internet]. 2015. acesso em 15 de Outubro de 2015]. Disponível em: http://www.revista.vestibular.uerj.br/artigo/artigo.php?seq_artigo=38

[3] Ministério da Educação. Instituto Nacional de Estudos e Pesquisas Educacionais Anísio Teixeira. Matriz de referência para o ENEM. Dis poní vel e m : <http://portal.mec.gov.br/index.php? option=com_docman\&view=download\&alias=841-matriz-1\&category_slug=documentos-pdf\&ltemid=30192>. Acessado em 25/05/2016 
[4] Barbão AJM, Oliveira IG. Utilização e compreensão da nomenclatura biológica por alunos do ensino médio da escola estadual Wilson de Almeida - Nova Olímpia/MT. In Anais do IV Fórum de educação e diversidade: "diferentes, (des)iguais e desconectados"; 13 a15 de junho de 2010. , Tangará da Serra, MT. Livro Digital IV Fórum de Educação e Diversidade. 2010. p 1-5.

[5] Siqueira LGG, Wechsler SM. Motivação para a aprendizagem escolar e estilos criativos. Campinas: ETD - Educação Temática Digital 2009; 10: 124-146.

[6] Murray EJ. Motivação e emoção. Rio de Janeiro: Guanabara-Koogan, 1986.

[7] Cruz SRR. Professores e mídias digitais: em busca da integração às práticas pedagógicas. Diálogos Educacionais 2010; 1(1): 41-50.

[8] Kishimoto, TM. O jogo e a educação infantil. In: (Org.). Jogo, brinquedo, brincadeira e educação. São Paulo: Cortez 1996.

[9] Miranda S. No Fascínio do jogo, a alegria de aprender. Ciência Hoje 2002; 28 (168): 64-66.

[10] Neto AADO, Benite-Ribeiro SA. Um modelo de role-playing game (rpg) para o ensino dos processos da digestão. Revista Eletrônica do curso de Pedagogia do Campus de Tajaí - UFG 2012; 13(2): 1-15.

[11] Cunha, HS. Brinquedo, desafio e descoberta. 1a edição. AE/MEC/RJ, 1998.

[12] Campos LML, Bortoloto TM, Felício AKC. A Produção de jogos didáticos para o ensino de ciências e biologia: uma proposta para favorecer a aprendizagem. Caderno dos Núcleos de Ensino. [periódicos na internet]. 2002. acesso em 22 de abril de 2015]. Disponível em: http://www.unesp.br/prograd/PDFNE2002/aproducaodejogos.pdf

[13] Santos PRD, Oliveira CMS. Ludicidade: uma prática de ensino, sendo vivenciada nas experiências do estágio supervisionado. In Anais do II Congresso de educação, IV Seminário de estágio e I Encontro do PIBID "paradigmas da profissão docente"; 28 a 30 de novembro de 2013. Iporá - GO. IV Seminário de Estágio. 2013, p.110-119

[14] Maluf ACM. Atividades lúdicas como estratégias de ensino aprendizagem. [periódicos na internet]. 2006. acesso em 22 de abril de 2015]. Disponível em: http://www.psicopedagogia.com.br/artigos/artigo.asp? entrID $=850$

[15] Cabrera WB. A Ludicidade para o ensino médio na disciplina de biologia: Contribuições ao processo de aprendizagem em conformidade com os pressupostos teóricos da Aprendizagem Significativa. Dissertação [Mestrado em Ensino de Ciências e Educação Matemática] - Universidade Estadual de Londrina. 2006.

[16] Zanon DAV, Guerreiro, MAS, Oliveira RC. Jogo didático Ludo Químico para o ensino de nomenclatura dos compostos orgânicos: projeto, produção, aplicação e avaliação. Ciência \& Educação 2008; 13: 72-81.

[17] Brasil. Ministério da Educação. Secretaria da Educação Média e Tecnológica. Parâmetros Curriculares Nacionais + $(\mathrm{PCN}+)$ - Ciências da Natureza, Matemática e suas Tecnologias. Brasília: MEC, 2002.

[18] Orlando TC, Lima AR, Silva AM, Fuzissaki CN, Ramosa CL, Machado D, Fernandes FF, Lorenzi JCC, Lima MA, Gardim S, Barbosa VC, Tréz TA. Planejamento, montagem e aplicação de modelos didáticos para abordagem de biologia celular e molecular no ensino médio por graduandos de ciências biológicas. Revista Brasileira de Ensino de Bioquímica e Biologia Molecular 2009; 1: A1-A17.

[19] Moroni FT, Moroni RB, Justiniano SCB, Santos JMM. Pescando nucleotídeos: um novo jogo educativo para o ensino do processo de síntese protéica para estudantes do ensino médio. Revista Brasileira de Ensino de Bioquímica e Biologia Molecular 2009; 1: D1-D5.

[20] Weyh A, Carvalho IGB, Garnero AV. Twister Proteico: uma ferramenta lúdica envolvendo a síntese de proteínas. Revista de Ensino de Bioquímica 2015; 13(1): 58-74.

[21] Gomes LMJP, Messeder JC. Fotossíntese e respiração aeróbica: vamos quebrar a cabeça? Proposta de jogo. Revista de Ensino de Bioquímica 2014; 12(2): 91-107.

[22] Vasconcellos CS. Metodologia dialética em sala de aula. Revista de Educação AEC 1992; 83: 1-18.

[23] Moratori PB. Por que utilizar jogos educativos no processo de ensino aprendizagem? Trabalho de Conclusão de Curso [Instituto de Matemática - Núcleo de Computação Eletrônica Informática na Educação] - Universidade Federal do Rio de Janeiro. 2003. 1997. 


\section{Agradecimentos}

Aos funcionários da Escola Estadual Ângelo Ramazzotti que foram muito receptivos durante nossa estádia na escola. A todos os alunos que participaram da aplicação e contribuíram com suas opiniões sobre o jogo e que responderam aos questionários. Ao Henrique de Souza Oliveira que nos auxiliou na criação do jogo durante a disciplina de Prática de Componente Curricular em Fisiologia. À Magda Rabelo de Souza e ao Emerson Luis Carneiro Merkel que nos ajudaram durante o aperfeiçoamento das regras do jogo. Também agradecemos as estudantes Vêronica Yasmin da Rocha Alecrim, Victória da Silva Mesquita e Wendell Marcelo. 
Apêndice A. Cartas do Fisio card game.
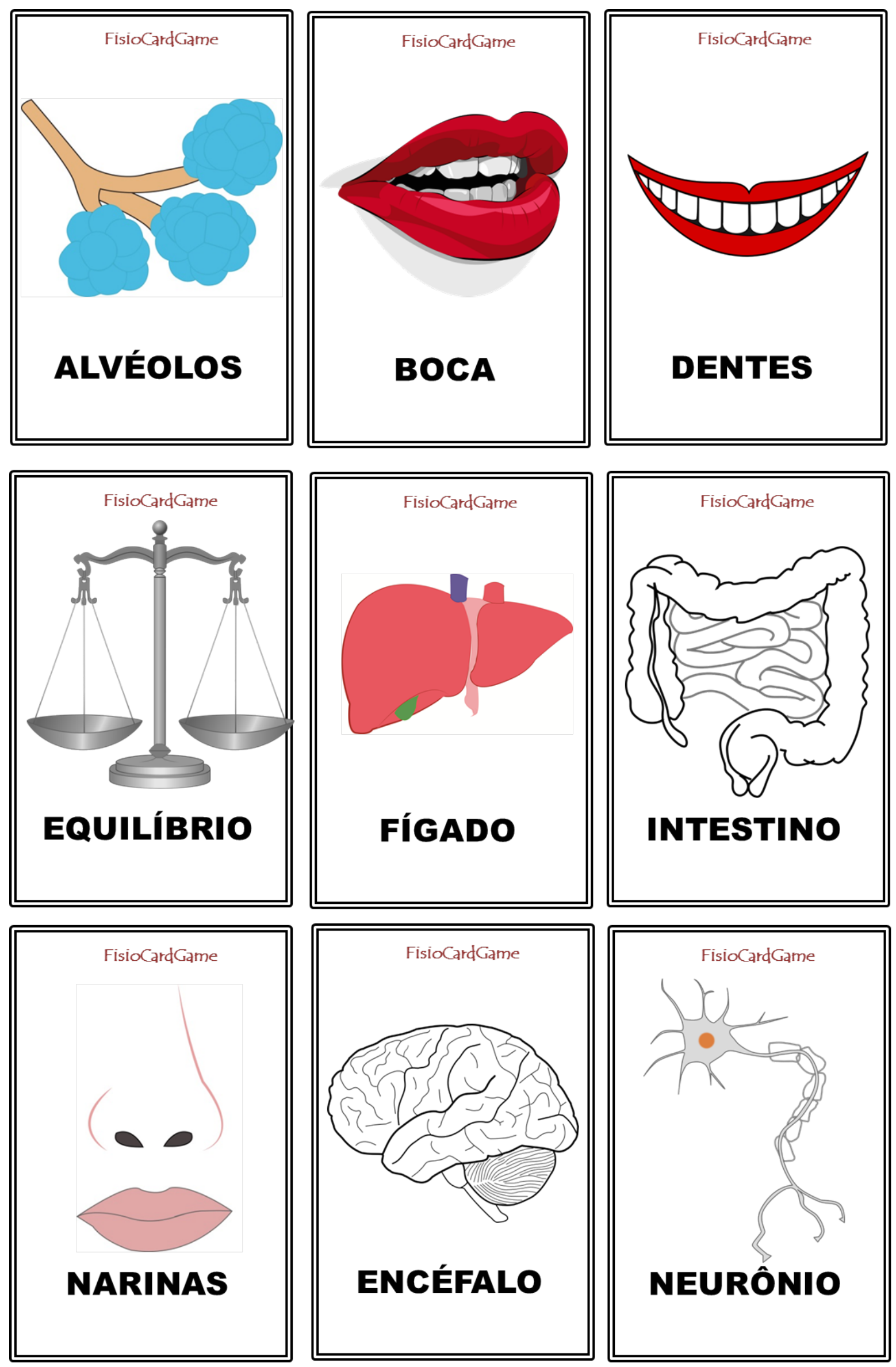

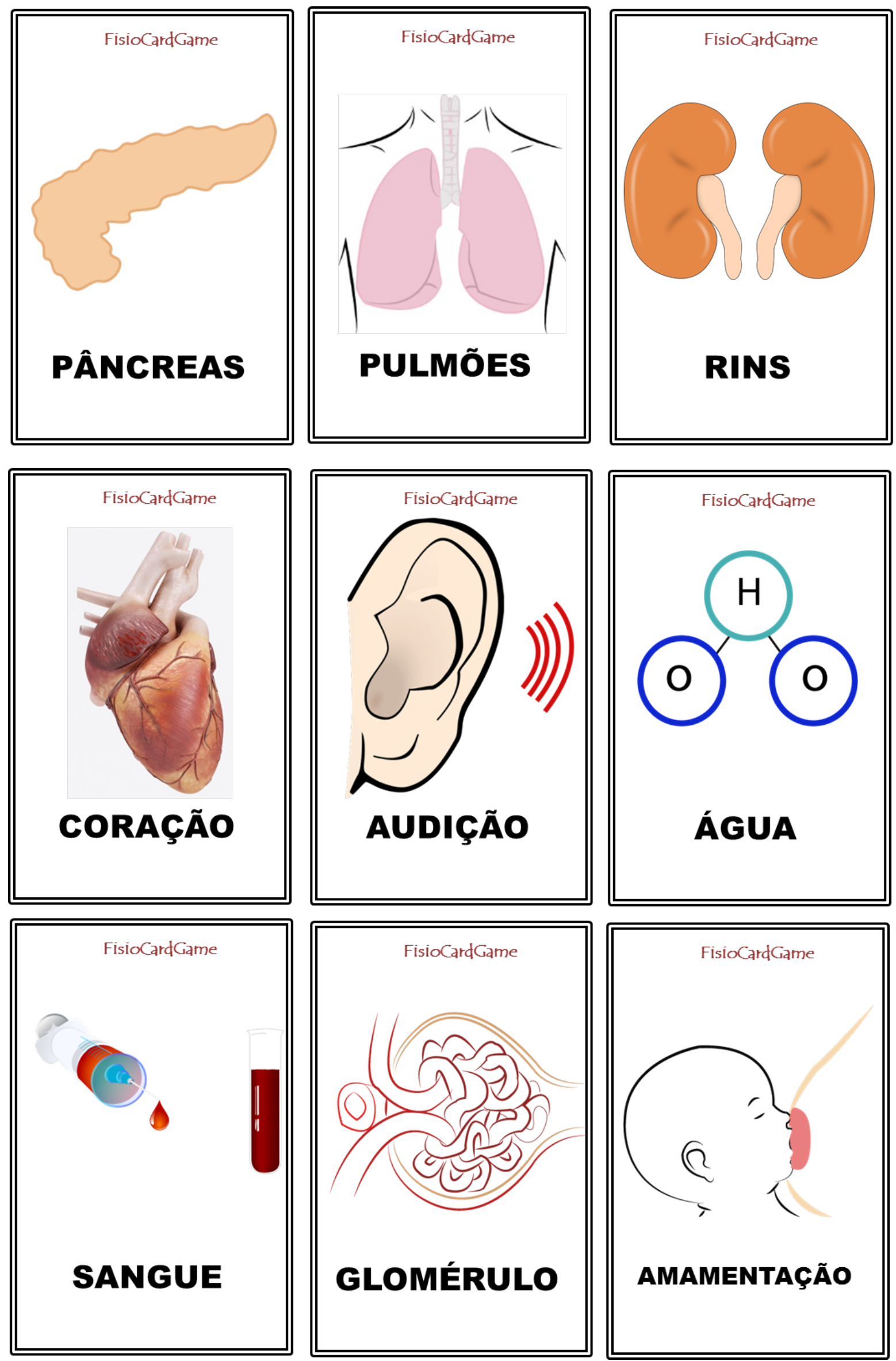

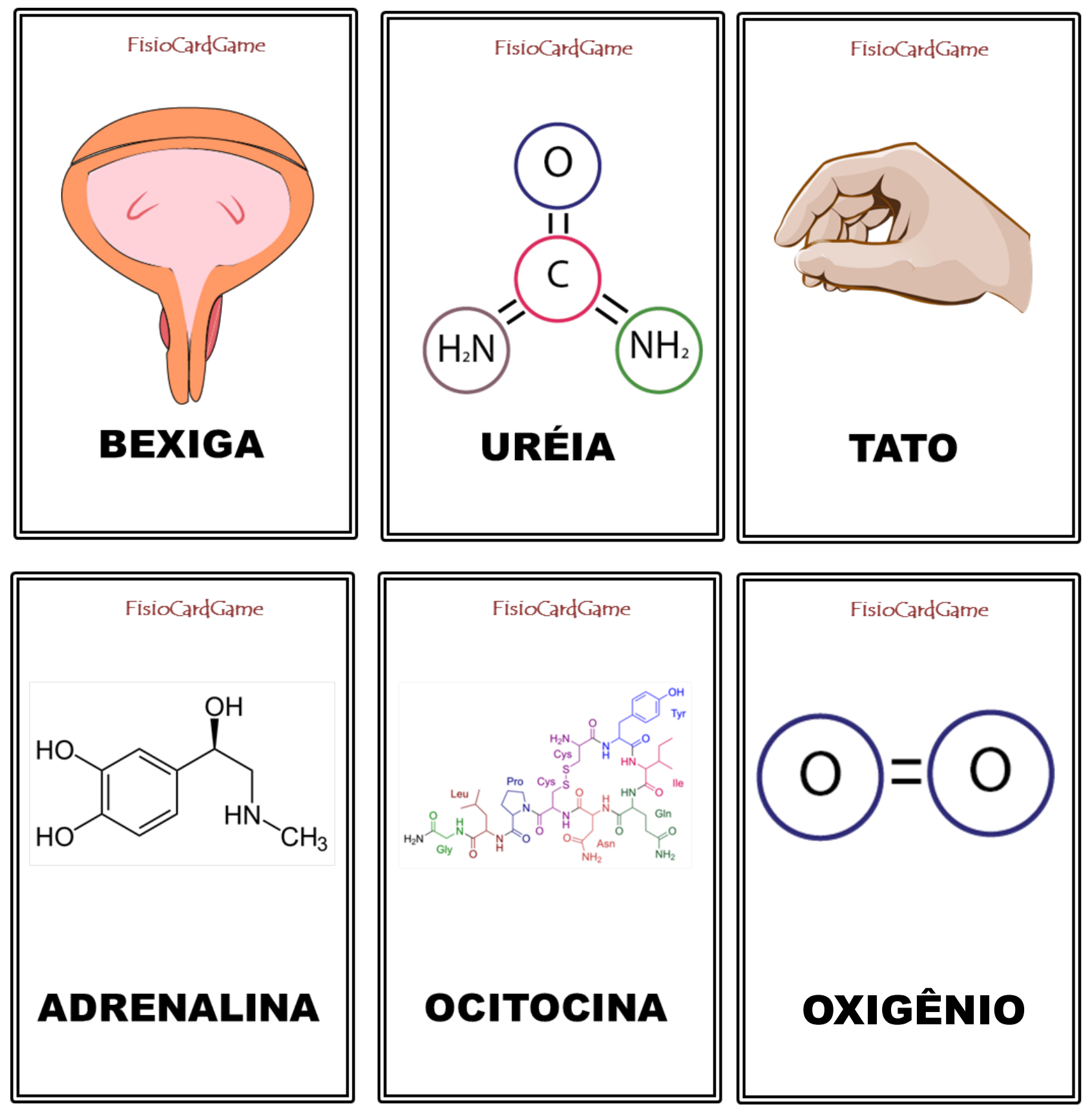

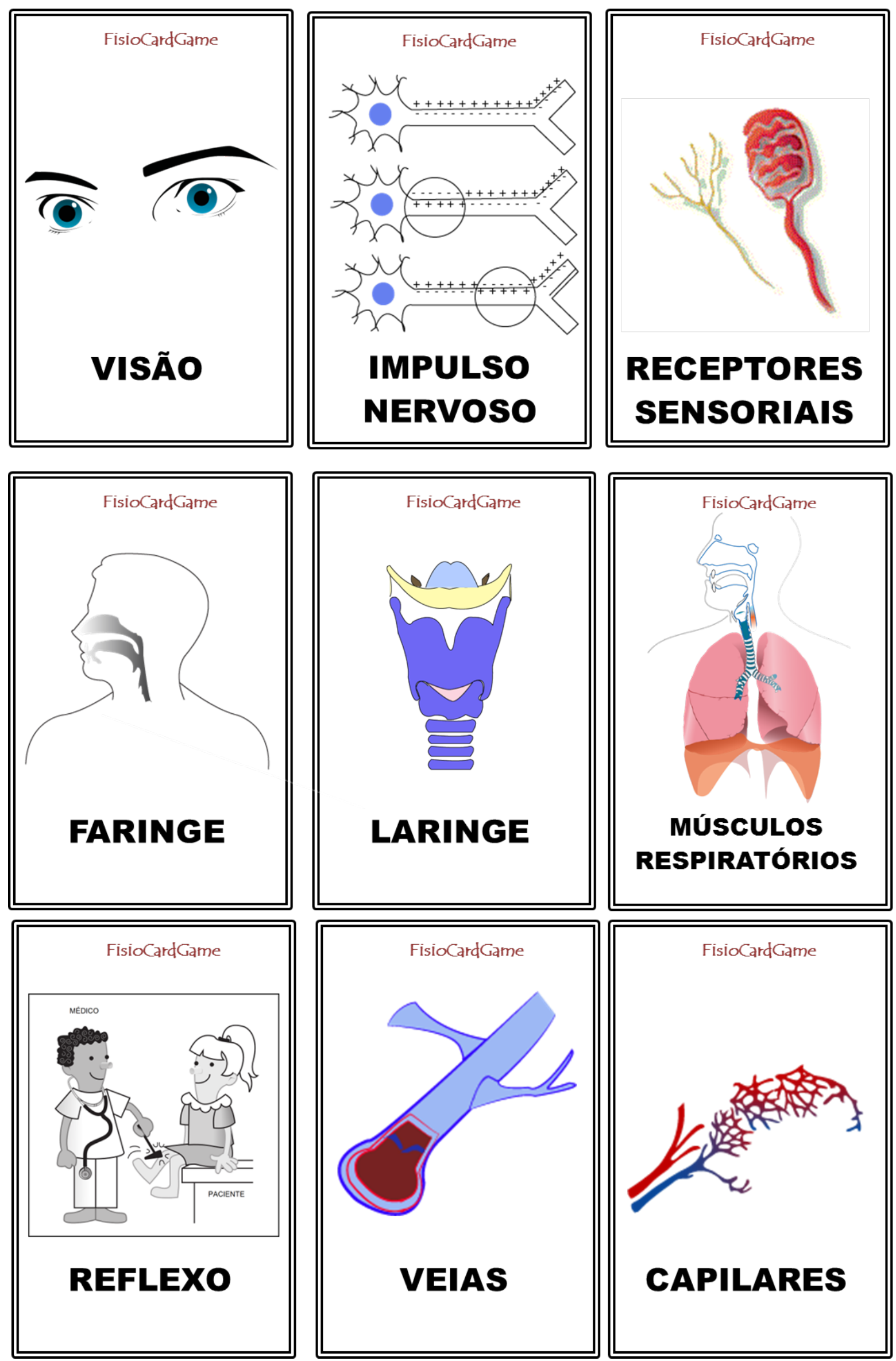

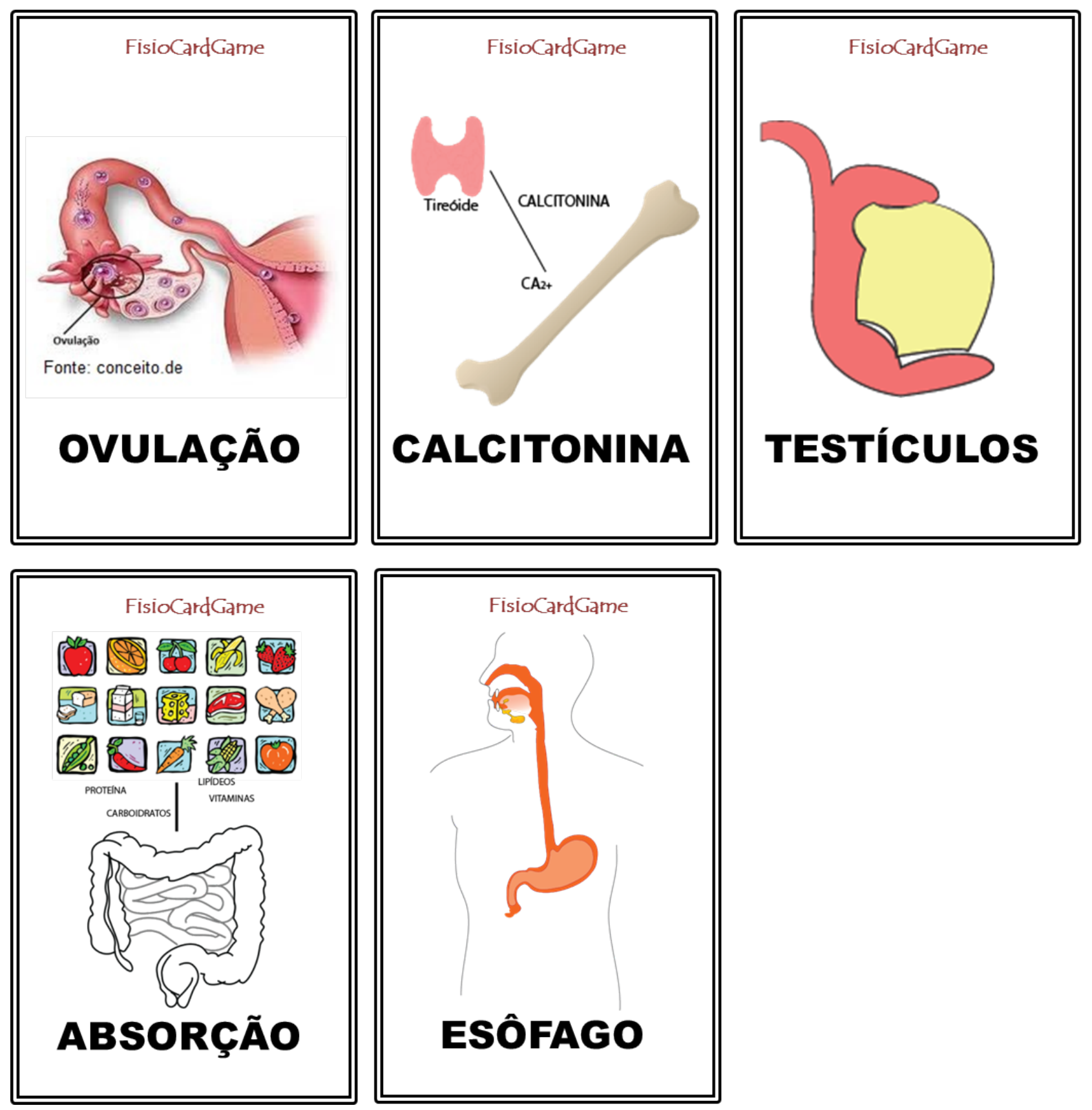

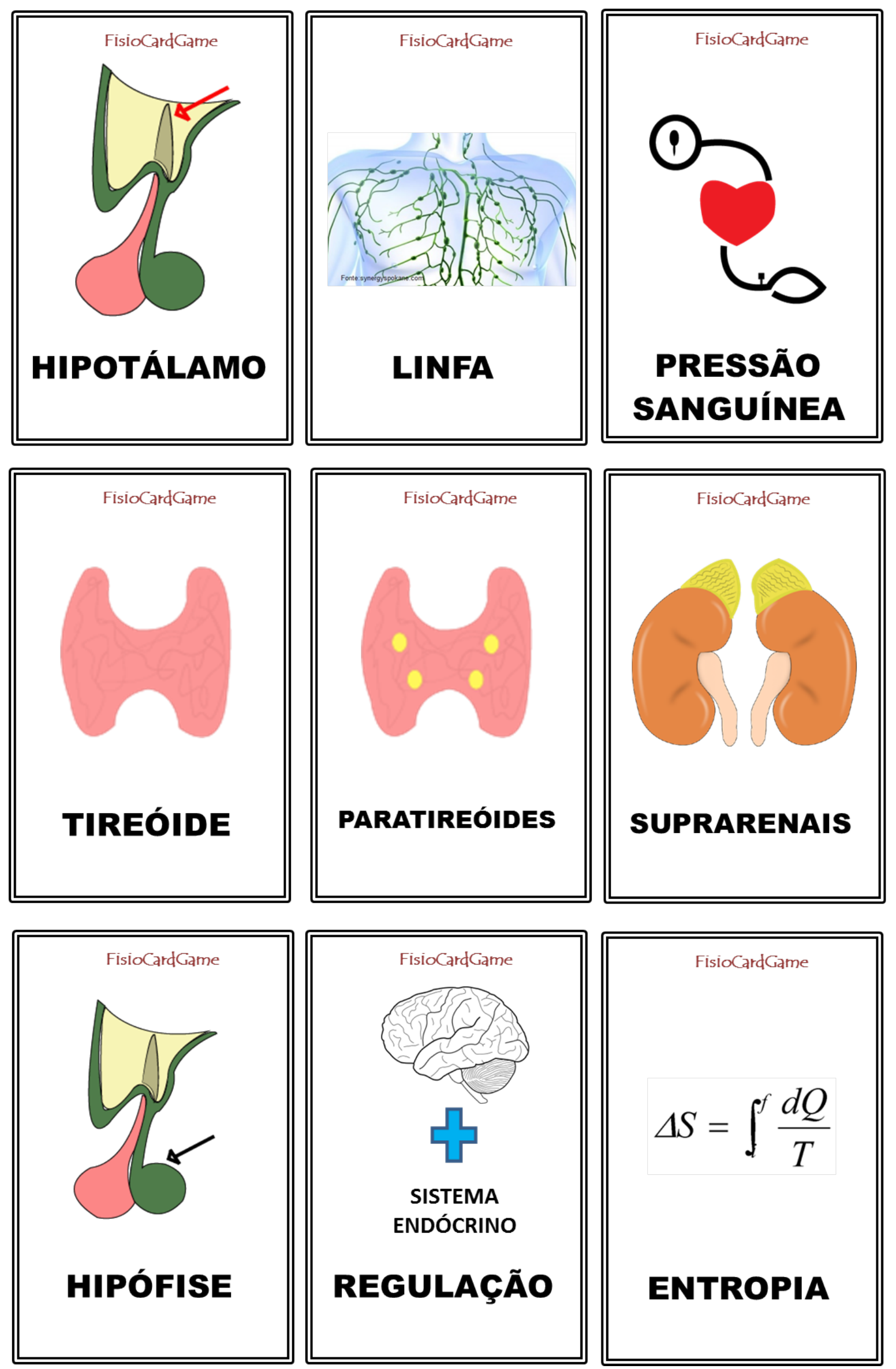

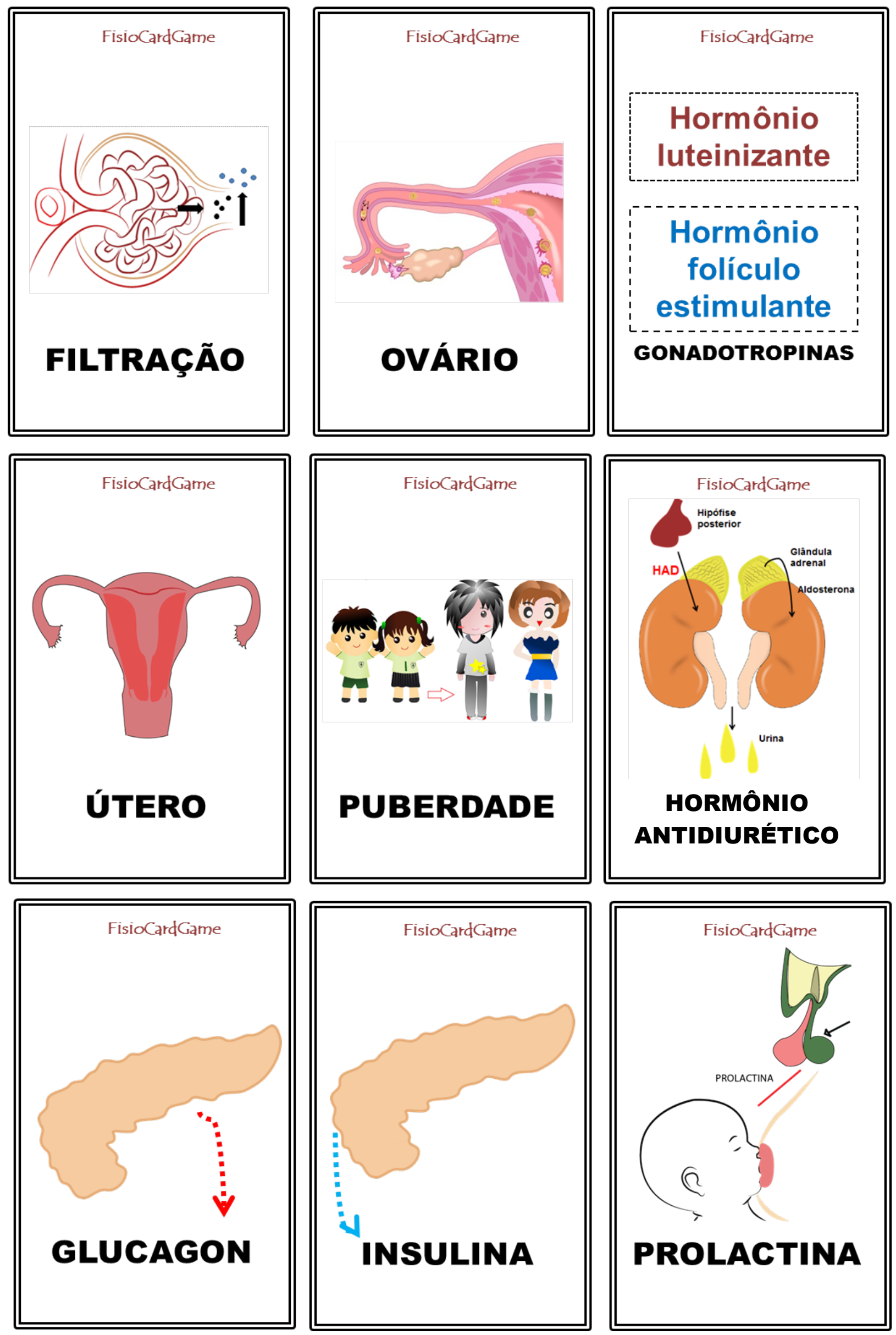
Apêndice B. Questionário Preliminar - Fisiologia

Para que este estudo seja válido, é importante que você responda cada questão de maneira cuidadosa e sincera. Todas as suas respostas serão CONFIDENCIAIS, sendo o preenchimento deste questionário ANÔNIMO. Lembramos que sua participação é de extrema importância para a realização deste estudo.

1) Quais são os sistemas que possuem função regulatória:
(a) Sistema Nervoso e Sistema Renal
(b) Sistema Nervoso e Sistema Circulatório
(c) Sistema Endócrino e Sistema Nervoso
(d) Sistema Respiratório e Sistema Nervoso.

2) Qual a unidade funcional do sistema respiratório?
(a) Alvéolos
(b) Dentes
(c) Néfrons
(d) Neurônios

3) A linfa é componente de qual sistema do corpo humano:
(a) Sistema Renal
(b) Sistema Circulatório
(c) Sistema Endócrino
(d) Sistema Respiratório

4) A integração entre todos os sistemas proporciona a
(a) Frequência Cardíaca
(b) Entropia
(c) Homeostase
(d) Pressão

5) Qual sistema é responsável pelo transporte de nutrientes e outras substâncias pelo organismo.
(a) Sistema Renal
(b) Sistema Circulatório
(d) Sistema Respiratório
(c) Sistema Endócrino que permite a vida nos seres humanos. 
Apêndice C. Questionários de compreensão - Fisiologia.

Para que este estudo seja válido, é importante que você responda cada questão de maneira cuidadosa e sincera. Todas as suas respostas serão CONFIDENCIAIS, sendo o preenchimento deste questionário ANÔNIMO. Lembramos que sua participação é de extrema importância para a realização deste estudo.

1)- Complete as sentenças com a alternativa correta:

(a) $\mathrm{O}$ é um orgão muito importante para o sistema , pois controla todos os outros sistemas, $\mathrm{O}$ é a célula responsável pela transmissão do

(_ cérebro, nervoso, neurônio, impulso nervoso.

(_ coração, nervoso, complexo de Golgi, estimulo cardíaco.

(_) pulmão, endócrino, hepatócito, impulso nervoso.

(_) coração, endócrino, hormônio, estimulo hormonal.

(b) A digestão inicia com a digestão mecânica através dos para passar pelo órgão tubular por onde o alimento passa e dá acesso a órgãos como o estômago e o ocorre a com a ajuda de substâncias produzidas por órgãos como

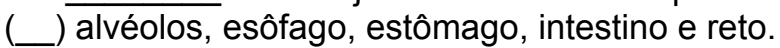

(_) dentes, estômago, intestino, circulação, pâncreas, pulmão.

(_) dentes, esôfago, intestino, absorção, pâncreas, fígado.

(__) alvéolos, estômago, esôfago, fígado e rins.

(c) O é um dos componentes mais essenciais para a vida na Terra, os humanos o conseguem por meio da contração de um que tem o papel de "puxar" o ar para dentro dos através da , tudo isso para que o ar chegue a unidade funcional do sistema respiratório, os onde este será absorvido pelos capilares.

(__ $\mathrm{O}_{2}$, músculo, pulmões, traquéia e néfrons

(_) $\mathrm{CO}_{2}$, músculo, pulmões, traquéia e alvéolos

(_ $\mathrm{O}_{2}$, músculo, pulmões, traquéia e alvéolos

(__ $\mathrm{CO}_{2}$, músculos, alvéolos, traquéia e pulmões

(d) O sistema circulatório tem a função de transporte de conduzido por meio de vasos como, por exemplo, as que é bombeado pelo que é um e onde os transportado irá depender da que retornam o sangue para o coração e leva, ele também é encarregado de fazer o transporte da sangue depois que o corpo o utilizou.

(__ sangue, coração, veias, capilares, pressão e linfa

(_) sangue, pressão, linfa, coração, veias e capilares

(__) sangue, coração, veias, capilares, pressão e $\mathrm{H}_{2} \mathrm{O}$

(__ $\mathrm{H}_{2} \mathrm{O}$, coração, veias, capilares, pressão e sangue

(e) Durante a nosso corpo sofre mudanças, em conseqüência da ação de hormônios, que são produzidos por órgão como e (onde ocorre a maturação dos óvulos, conhecida por ). Nos homens, essas mudanças ocorrem pela produção de testosterona nos

(_) puberdade, ovário, útero, ovulação, testículos

(__) puberdade, ovulação, ovário, útero, testículos

(__) puberdade, testículos, útero, ovário, ovulação

(__) ovulação, ovário, útero, testículos, puberdade

2)- Em sua opinião o jogo foi divertido?

3)- De que maneira o jogo auxiliou a compreender um pouco mais sobre a fisiologia humana?

4)- Quais os pontos positivos e negativos do jogo?

5)- Você gostaria de ter jogado após as aulas de fisiologia? 